\title{
Editorial
}

\section{How to get an article accepted for publication?}

\author{
SS Jha ${ }^{1, *}$ \\ ${ }^{1}$ Dept. of Orthopaedic, Harishchandra Orthopaedic Research Institute, Patna, Bihar, India
}

\section{A R T I C L E I N F O}

Article history:

Received 17-12-2020

Accepted 30-12-2020

Available online 15-01-2021
This is an Open Access (OA) journal, and articles are distributed under the terms of the Creative Commons Attribution-NonCommercial-ShareAlike 4.0 License, which allows others to remix, tweak, and build upon the work non-commercially, as long as appropriate credit is given and the new creations are licensed under the identical terms.

For reprints contact: reprint@ipinnovative.com

\section{Introduction}

Critically analyzing a manuscript submitted for publication has pondered me over the years regarding the various issues concerning the articulation, grammar, sentence construction, and other technical details qualifying them for acceptance for publication. This has prompted me to come out with the following article as editorial, which should help the authors in stitching together various aspects of an article structurally before submission and answers various issues raised commonly irrespective of the topic of the article.

\section{Publication Cycle}

Editors, undoubtedly play a crucial role in the publication process. Throughout the publication cycle, they are the single point of contact for the authors. What is more important and relevant is that the authors heavily rely on them. They represent everything that the journal stands for. A well-documented manuscript is a key to get clearance from the editor for acceptance of an article for publication. It throws multiple challenges to the author. The author must be conversant with the editorial process involved before publication. The entire process can be summed up into five stages:-

Stage 1 Pre-submission inquiry and pre-screening - Is the manuscript within the scope of the journal?

\footnotetext{
* Corresponding author.

E-mail address: drssjha@gmail.com (S. S. Jha).
}

Stage 2 Peer review and revision - Approval of two or three reviewers are obtained for one manuscript.

Stage 3 Acceptance for publication

Stage 4 Technical - Copy editing, layout, and proofreading

\section{Stage 5 Publication}

As it is evident from the above stages, stage 3 is the definitive stage from both author and editor's point of view, and the decision regarding acceptance for publication is finally concluded. Stage 4 and 5 are the onus of the publisher. Stage 1 and 2 are concerned with the identification of potential two or three reviewers and finally getting their approval for reviewing one manuscript becomes most essential.

The manuscript, apart from being an article for publication in the journal, could also be either conference proceedings, book manuscripts, grant proposals, teaching portfolios, promotion decisions, or program accreditation.

\section{Expectations from the Author}

Expectations from the author by the reviewer and editor encompass critical analysis of authors' reporting standards. There must be originality in his research work and plagiarism must not cross the permissible limit. The author must have data access along with retention. He must acknowledge the source and simultaneously must be conscious of multiple redundant and concurrent publications. There could be multiple authors in an article 
but each author should take responsibility for a specific part of the work. An international collaboration of authors is the most preferred joint authorship for a work providing credibility to the research performed at two centers.

\section{Obligations of Reviewer and Editor before acceptance}

A reviewer and the editor both have a common code of conduct wherein they are obliged to maintain confidentiality and simultaneously must disclose conflict of interest. A reviewer has a complimentary role as their contribution to the editorial decision is paramount but at the same time, the editor expects him to be prompt as well. The editor himself has to follow the ethical standards and must have fair play in his publication decision.

\section{What is the editorial process?}

The editorial process is a highly subjective process by which the content of the write-up is created. The editorial process is "iterative" which involves doing something again and again or one of the times usually to improve the designing of the write-up. This helps also in the separation of content from simple data or information. Invariably, the editorial process often also consists of "shepherding" content through the content lifecycle. The editor cannot be dogmatic enough to fill all write-ups through the same yardstick. He has to employ a varied and flexible approach in making his judgment according to the merit of each writeup.

\section{Are editors \& authors aligned?}

Two moot questions still arise vis a vis the Editors and Authors "Do authors know exactly what journal editors want?" and "Do journal editors really understand the challenges the authors face?" Unfortunately, the answer to both is simply "no". This cleavage is mostly regarding the journal instructions, while the authors are not really happy about their clarity and compliances, invariably the authors have a favorable opinion regarding them. The author's thinking always puts a question mark on the efficiency of journal systems and processes. The authors claim to understand the publication ethics and standard guidelines. The authors also feel that they address carefully all comments of the peer-reviewer. The editors think that the journal systems, processes a-re author-friendly, and the authors do not follow journal instructions well. The editors are of the view that authors do not realize the importance of publication ethics and the authors only respond to the agreeable comments of the peer reviewer and keep silent on the rest of the comments.

\section{How Editors can bridge the gap}

Bridging the gap will benefit both the authors and editors. Clear author guidelines have to be provided and an authorfriendly journal process has to be set-up. The editors must have clarity while communicating with authors.

It is a common observation that some write-ups are summarily rejected without review but this

"pre-screening exercise" looks into:-

1. Whether the manuscript falls within the framework of the journal's guidelines, aims, and scope.

2. Word limits, figures, tables, authorship, and criteria are all looked into.

3. Plagiarism is the most important aspect which is verified and must not cross the prescribed limit.

4. The pre-screening ensures retaining manuscripts with potential.

5. This pre-screening also lessens the chances for a manuscript to dwell unproductively in an unsuccessful cycle of peer review.

6. Final sorting leads to the selection of a provisional publishable article, which is sent to the reviewer.

\section{Editor's advice to the reviewer}

Editors want their reviewers to be critical and want them to read the "abstracts" first to examine whether the author's statement makes logical sense and also make a judgment regarding the comprehensible manner of their writing. They are also directed to report whether something new in the "observation" has been reported in the submitted manuscript. Next, tables and figures are to be examined to see whether the "legends" corroborate with clarity the expressions in the figures and tables. Then, comes the evaluation of "statistical analysis" to find whether it makes sense. The reviewers are further advised to examine the "methods" to make sure that the author knew what they were doing. Lastly, the reviewer is advised to read "the discussions" and see if it makes sense, and whether it reflects the data in the article presented. Any unnecessary conjecture or unfounded conclusions not based on "evidence" must be taken note of. A final comment is to be made whether the manuscript is concise or wellorganized.

\section{What journal reviewer looks for?}

Apart from the appropriateness of the work for the journal, importance and broad interest of the subject, and clarity of the writing, the reviewer looks for quality of the data, the extent of the data support and conclusions made, completeness of the citation, and the novelty and the importance of the work described. 


\section{Methods of Peer Review}

It could be single-blind or double-blind. In a single-blind review, the author does not know the identity of a reviewer whereas, in a double-blind review, both the author and reviewer do not know either's identity and hence, provide an honest review without any fear of retribution.

\section{Reviewer's comments}

Peer review is the backbone of the editorial process of any journal and is an essential part of the publishing process. It identifies the weakness and strength of ideas and approaches in the manuscript. It is an evaluation process by which an expert critically analyses the work of the individual or groups seeking recognition, publication, or funding of any journal and forms the cornerstone of scientific publication. The peer reviewers should not have a conflict of interest in peer review regarding that particular manuscript.

Reviewer sometimes before making a final decision may make the following comments:-

1. Lack of clarity in writing

2. The logic of the argument is unclear

3. The author is unaware of relevant existing work

4. The author misinterprets existing research

5. Data is not convincing

6. Contribution to the research is not apparent

\section{Final recommendation of a reviewer}

After validation and confirmation of research work, the reviewer makes one of the three recommendations:-

1. Acceptance of the manuscript.

2. Rejection of the manuscript.

3. Suggestion for a minor or major revision of the manuscript.

\section{Editor's dilemma after peer review}

On contradictory reports from two or three peer reviewers, the editor is convinced that the manuscript has been entirely misinterpreted by the reviewer, he is obliged to appoint another reviewer or arbitrator to reach a final decision before acceptance or rejection of the manuscript. Journal editors look for a "wow factor" in the subject or theme that sheds light or gives insight. The manuscript's clarity, correct formatting fitting within the scope of the journal, novelty in its value of practical research, and their theoretical implications are the four pillars worth consideration by the editor.

\section{Avoidable frequently occurring problems}

Authors should refrain from avoidable frequently occurring problems. Papers are submitted which are clearly out of the scope of the journal. Authors have failed to format the papers according to the style of the journal. Suggested reviews are either inappropriate or not mentioned. Authors do not respond or respond inadequately to the reviewer's queries. The rejected manuscripts are re-submitted without revision. Lastly, submissions are made with inadequate language standards for publication.

There will be lesser chances of authors misunderstanding the editors if they would know what is expected from them and they will follow the best publication practice. The author should prepare a better submission package conforming to all the journal guidelines. Their journal submission becomes a confident effort if the author has easy access to all essential information.

The editors should encourage the authors to follow best publication practice, such that they are seen as "advisors" and "thought-provoking leaders". With the improvement of the quality of the submission, a cleaner journal process evolves which reduces clutter and sets up a smoother submission cycle. This also necessitates the desirability of reduced offline communication. Before submitting an article, the author must make sure that it is "as good as he can". This practically makes things easier for both the reviewers and editors and the chances of acceptance of the article are increased.

\section{Usual missive to authors}

The paper must not be sent to the wrong journal and guidelines must be adhered to. Such manuscripts do not get published because they were not good papers rather because they were sent to the wrong journal.

Before submission, authors are advised to pay attention to the ethical standards and be honest with themselves. While correct English is of paramount importance, it must be ensured that the article is proofread by the author's colleagues. It is a healthy practice to keep the manuscript in your drawer once it is ready and forget it. After two weeks, take it out from the drawer and critically re-evaluate your manuscript, and make suitable changes by being selfcritical. Authors are advised to pay attention to details and double-check the manuscript so that it is worth presentation. Any help received must be acknowledged.

After getting the reviewer's comments, authors are advised to respect them and reply accordingly. Time must be spent while revising the manuscript. The gold standard manuscript submission is a concise, direct, new, original, and previously unpublished one. Editors are also human and at the same time, they are conscious of maintaining the reputation of their journal at the top and hence look for top articles. Title, abstract, and conclusion are invariably the first to be visited by the editor and reviewer and hence, their structuring becomes important. Similarly, reviewers like any other person are usually short of time but simultaneously desire to favor only the ideal article and hence, get delayed 
in clearing the article.

Articles must have a message, but should not encompass more than three. "Title" of the article is an important pillar that drives both the editor and the reviewer for looking into the subsequent details. Fabrication of a proper structure must be used to promote the article and it encourages citation of the article, too. It is finally advised not to be impatient before receiving an acceptance letter or otherwise, because post-submission paraphernalia concerning the quality of content, the impact factor, and the verification of author-supplied references, do take time.

The world is itching to come out from the shadows of the pandemic of COVID-19 and the long-awaited vaccines seem to be around the corner in all the countries but the process of vaccination itself is going to be a tough task and may consume nearly another year. Luckily, knowledge in every field has flourished in these times, and interactions on webinars have been conducted endlessly to further advance developments in all the fields.

I personally congratulate all the contributors to this issue for their valued articles. I do take this opportunity for wishing a happy new year 2021 as being a year of hope leading to the clearing of the COVID cloud this year itself.

\section{Acknowledgment}

Ms. Nikita Pandit, Founder, and Director of Innovative Publication.

\section{Author biography}

SS Jha, Director

Cite this article: Jha SS. How to get an article accepted for publication?. IP Int J Orthop Rheumatol 2020;6(2):41-44. 